Liver, Pancreas and Biliary Tract

\title{
Kinetics of hepatitis C virus RNA decay, quasispecies evolution and risk of virological failure during telaprevir-based triple therapy in clinical practice ${ }^{\text {负 }}$
} \author{
Luca Carioti ${ }^{a}$, Francesco Paolo Antonucci ${ }^{a}$, Ada Bertoli ${ }^{g}$, Francesca Trave ${ }^{\mathrm{b}}$, \\ Jacopo Vecchiet ${ }^{\mathrm{c}}$, Giustino Parruti ${ }^{\mathrm{b}}$, Sergio Babudieri ${ }^{\mathrm{e}}$, \\ Carlo Federico Perno ${ }^{\mathrm{a}, \mathrm{g}}$, Francesca Ceccherini-Silberstein ${ }^{\mathrm{a}}$ \\ a Department of Experimental Medicine and Surgery, University of Rome "Tor Vergata", Rome, Italy \\ ${ }^{\mathrm{b}}$ Infectious Disease Unit, Pescara General Hospital, Pescara, Italy \\ ' Infectious Disease Clinic, Chieti, Italy \\ d Department of Economics, Institutions and Law, University of Rome "Tor Vergata", Rome, Italy \\ e Infectious Diseases Unit, Department of Clinical and Experimental Medicine, University of Sassari, Italy \\ ${ }^{f}$ Pharmacology Unit, “A. Gemelli" Hospital, Rome, Italy \\ ${ }^{\mathrm{g}}$ Molecular Virology Unit, University Hospital of Rome "Tor Vergata", Rome, Italy

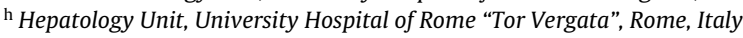 \\ ${ }^{i}$ Goodman Faculty of Life Sciences, Bar-Ilan University, Israel
}

Valeria Cento $^{\mathrm{a}, *}$, Monica Tontodonati ${ }^{\mathrm{b}, \mathrm{c}}$, Velia Chiara Di Maio ${ }^{\mathrm{a}}$, Maria Concetta Bellocchi ${ }^{\mathrm{a}}$, Fabrizio Valenti ${ }^{\mathrm{d}}$, Alessandra Manunta ${ }^{\mathrm{e}}$, Serena Fortuna ${ }^{\mathrm{f}}$, Daniele Armenia ${ }^{\mathrm{a}}$, Pierluigi Cacciatore $^{\mathrm{b}}$, Mario Angelico ${ }^{\mathrm{h}}$, Pierluigi Navarra ${ }^{\mathrm{f}}$, Avidan U. Neumann ${ }^{\mathrm{i}}$,

\section{A R T I C L E I N F O}

\section{Article history:}

Received 8 July 2014

Accepted 3 December 2014

Available online $\mathrm{xxx}$

\section{Keywords:}

Drug-resistance

Mathematical modelling

Protease inhibitors

Viral kinetic

\begin{abstract}
A B S T R A C T
Background: The used first generation protease inhibitors may be hampered by virological failure in partially interferon-sensitive patients.

Aim: To investigate early hepatitis C virus (HCV)-RNA decay and quasispecies modifications, and disclose viral dynamics underlying failure.

Methods: Viraemia decay at early time-points during telaprevir treatment was modelled according to Neumann et al. (1998). NS3-sequences were obtained by population-sequencing and ultradeep-454pyrosequencing.

Results: 13 treatment-experienced ( 8 non-responders, 5 relapsers), and two cirrhotic naïve patients, received telaprevir + pegylated-interferon- $\alpha+$ ribavirin

Viraemia decay was biphasic. In all patients, first-phase was rapid and consistent, with a median [interquartile-range] viraemia decay of $2.8[2.6-3.2] \log \mathrm{IU} / \mathrm{ml}$ within $48 \mathrm{~h}$. Second-phase decay was slower, especially in failing patients: $3 / 3$ showed $<1 \log \mathrm{IU} / \mathrm{ml}$ decay between $48 \mathrm{~h}$ and 2 weeks, and HCV-RNA $>100 \mathrm{IU} / \mathrm{ml}$ at week 2 . Only one patient experiencing sustained viral response showed similar kinetics.

By pyrosequencing, mutational freeze was observed in all 15 patients within the first $24 \mathrm{~h}$, but only in patients with sustained response afterwards. Indeed, $2 / 2$ failing patients showed early resistance, as minor (V36A-T54A: prevalence $<26 \%$ at $48 \mathrm{~h}$ ) or major (V36M/A-R155K: prevalence, $99.8 \%$ at week 2) variants.

Conclusions: Following telaprevir administration, first-phase HCV-RNA decay is consistent with mutational freeze and limited/no viral replication, while second-phase is significantly slower in failing patients (with appearance of resistance), suggesting the usefulness of early HCV-RNA monitoring.
\end{abstract}

(c) 2014 Editrice Gastroenterologica Italiana S.r.l. Published by Elsevier Ltd. All rights reserved.

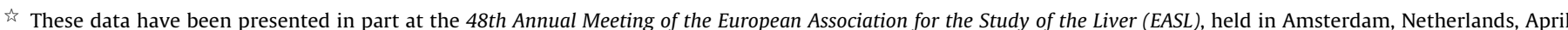
24-28, 2013 and at the The Liver Meeting® 2014 American Association for the Study of the Liver, November 1-5 2013, Washington DC, USA.

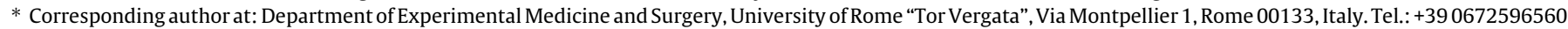
fax: +390672596039.

E-mail address: valeriacento@gmail.com (V.Cento).
} 


\section{Introduction}

In hepatitis $\mathrm{C}$ virus (HCV) infection, the development of directly acting antiviral agents (DAAs) provides an outstanding opportunity to improve cure rates for patients with chronic hepatitis $C$, allowing hopes for a large-scale eradication of HCV infection. The introduction into clinical practice of first-generation $\mathrm{HCV}-1$ protease inhibitors (PIs) improved treatment outcomes when added to pegylated interferon- $\alpha$ (pegIFN) and ribavirin (RBV) in both treatment-naïve and treatment-experienced patients [1-4]. Nevertheless, triple therapy, particularly for difficult patients, is often limited by safety and tolerability issues, which limit its use, along with a rapid onset of drug-resistance in virological failures. Paradoxically, drug-resistance is considered a hallmark of antiviral drugs, and de facto is both a major cause and consequence of virological failure $[5,6]$.

Within an infected individual, the high in vivo HCV mutation rate $\left(2.5-3.2 \times 10^{-5}\right.$ per nucleotide per genome replication round) [7], in synergy with a short half-life, and an extremely high daily viral production rate ( $10^{12}$ particles/day) leads to the generation of a swarm of genetically distinct but closely related viral variants, known as quasispecies [8]. In this heterogeneous viral population, the probability to have at least one viral strain harbouring one or two nucleotide mutations is close to $100 \%$ [9].

In an "ideal scenario", with completely wild-type and sensitive viral quasispecies, viral eradication by treatment follows a biphasic profile: in the first phase viral particle production is steeply blunted, completely blocking viral replication in the liver, then in the second phase all infected cells are cleared, either by cell-death or loss of replicative intermediated (i.e. "cell cure"). Mathematical models estimated that, in this ideal situation, 8 weeks of telaprevir-based therapy would be enough to cure $99 \%$ of HCV-infected patients [10].

Nevertheless, when an anti-HCV agent is used against an "actual scenario" of viral quasispecies, drug-effectiveness in blocking viral production may not be $100 \%$ and minority resistant variants in the liver can consequently get the chance to replicate. When replication under positive selecting pressure is allowed, it increases the risk of generating viral variants with better resistant profiles and viral fitness.

In the past, mathematical models of HCV dynamics have contributed in understanding the mechanisms of action of IFN, pegIFN and pegIFN + RBV, and consequently in better characterising viral behaviour under drug pressure [11-13]. Recently, dynamic parameters have been estimated in patients treated with DAAs, particularly in monotherapy [14]. However, so far no data are available on the effects of PI-based triple therapy in real clinical practice, often including difficult-to-treat patients who may actually have the greatest need of treatment, especially in Europe.

For all these reasons, the aims of this study were to describe the dynamics of genotype $1 \mathrm{HCV}$-RNA decay within the first hours and days of telaprevir-based triple therapy in treatment-experienced and/or cirrhotic patients, and to simultaneously evaluate the early modifications in the quasispecies population by mean of ultrasensitive techniques, correlating both factors with the clinical situation, plasma telaprevir concentration, and therapeutic outcome.

\section{Materials and methods}

\subsection{Study population}

Chronically infected HCV genotype 1 patients, starting a tripletherapy with PegIFN/RBV plus telaprevir between June 2012 and November 2012, who consented to frequent blood sampling were considered for inclusion. Exclusion criteria were age under 18 years and other concomitant chronic liver diseases. Treatment schedules and stopping rules followed telaprevir prescribing information [15].

The analysis was performed in 15 patients (Table 1 ). Of these, 13 had previously failed a pegIFN + RBV treatment as non-responders (7 null-responders and 1 partial-responder), or as relapsers $(N=5)$. The other $2 / 15$ patients were cirrhotics naïve to treatment. Correlation of treatment outcome with viral kinetics was performed with a per protocol approach. This study was conformed to local ethical considerations and the principles outlined in the 1975 Declaration of Helsinki (6th revision, 2008). All patients allowed the participation to the study with a written consent for the use of samples for research purposes.

\subsection{HCV-RNA quantification}

Serum HCV-RNA was quantified by Roche $\operatorname{COBAS}^{\circledR}$ TaqMan $^{\circledR}$ HCV Test v2.0 (lower limit of quantification: $25 \mathrm{IU} / \mathrm{ml}$; LLOD, lower limit of detection: $15 \mathrm{IU} / \mathrm{ml}$ ) at baseline, at very early time points after telaprevir + pegIFN + RBV start $(1 \mathrm{~h}-2 \mathrm{~h}-3 \mathrm{~h}-4 \mathrm{~h}-$ 5h-6h-8h-12h-24h-28h-48h-1w-2w) and during per protocol follow-up.

\subsection{Mathematical modelling of HCV dynamics}

A constant-effectiveness (CE) model was used to fit observed data [11]. In order to normalise fluctuations, baseline HCV-RNA values were calculated as a mean among 2-3 pre/post-therapy measurements (baseline-1h-2h after triple-therapy start).

Viral load data were also tested for fitting with a model with varying-efficacy or intracellular dynamics [16], but the sampling frequency did not allow enough information to make a significant difference respecting to the standard bi-phasic model.

\subsection{Population sequencing}

NS3-protease sequences (aa 1-181) were obtained by an home-made sequencing protocol [17] at baseline and at early time-points ( $8 h-12 h-24 h-48 h-1 w-2 w-4 w)$, where plasma samples were available and HCV-RNA was detectable, and then in case of virological failure.

\subsection{Ultra-Deep 454-Pyrosequencing (UDPS)}

NS3-protease UDPS was performed in all patients at baseline. Tests at $8 \mathrm{~h}-12 \mathrm{~h}-24 \mathrm{~h}-48 \mathrm{~h}$ were performed in all available plasma samples with adequate HCV-RNA. Detailed information is reported in Appendix A. Briefly, 454 junior platform was used with 2 genotype specific protocols based on 2 overlapping amplicons spanning the entire NS3-protease-sequence. For each amplicon, reads were aligned and corrected using home-made Perl scripts and Shorah package [18]. By using a plasmid control, mutations found with frequency $>0.1 \%$, both in reverse and forward orientations were considered reliable. Global haplotype reconstruction was performed using Shorah package.

\subsection{Genetic diversity analysis}

Evolutionary divergence between sequences was calculated on NS3-sequences from population-sequencing and on UDPSamplicons using the Tamura 3-parameter model. The variation rate among sites was modelled with a gamma distribution (shape parameter $=1$ ). Codon positions included were $1 s t+2 n d+3 r d+$ Noncoding. All positions with $<95 \%$ site coverage were eliminated. Phylogenetic-trees were contextually inferred. All phylogenetic analyses were performed with MEGA v5.1 [19]. 
Table 1

Characteristics of the study population.

\begin{tabular}{|c|c|c|c|}
\hline & \multirow[t]{2}{*}{ Naïve cirrhotic patients $(N=2)$} & \multicolumn{2}{|c|}{ Treatment experienced patients $(N=13)$} \\
\hline & & Non-responders $(N=8)$ & Relapsers $(N=5)$ \\
\hline Age (years), Median (IQR) & $59(55-62)$ & $52(46-58)$ & $66(65-69)$ \\
\hline Males, $N(\%)$ & $1(50.0)$ & $7(87.5)$ & $3(60.0)$ \\
\hline \multicolumn{4}{|l|}{ IL-28B genotype, $N(\%)$} \\
\hline $\mathrm{CC}$ & $0(0.0)$ & $1(12.5)$ & $0(0.0)$ \\
\hline $\mathrm{CT}$ & $1(50.0)$ & $5(62.5)$ & $1(20.0)$ \\
\hline TT & $0(0.0)$ & $1(12.5)$ & $0(0.0)$ \\
\hline Not determined & $1(50.0)$ & $1(12.5)$ & $4(80.0)$ \\
\hline \multicolumn{4}{|l|}{ HCV-genotype, $N(\%)$} \\
\hline $1 \mathrm{a}$ & $1(50.0)$ & $4(50.0)$ & $0(0.0)$ \\
\hline $1 \mathrm{~b}$ & $1(50.0)$ & $4(50.0)$ & $5(100)$ \\
\hline Patients with cirrhosis, $N(\%)$ & $2(100)$ & $3(37.5)$ & $0(0.0)$ \\
\hline Baseline $\log _{10}$ HCV-RNA (IU/ml), Median (IQR) & $5.5(5.1-5.8)$ & $6.0(5.5-6.7)$ & $5.5(4.5-5.8)$ \\
\hline Baseline AST (IU/ml), Median (IQR) & $72(68-75)$ & $71(53-96)$ & $89(68-106)$ \\
\hline Baseline ALT (IU/ml), Median (IQR) & $81(65-97)$ & $105(68-149)$ & $118(78-187)$ \\
\hline
\end{tabular}

HCV, hepatitis C virus; IU, international units; IQR, interquartile range; ALT, alanine transaminase; AST, aspartate transaminase.

Genetic complexity was also evaluated by Shannon entropy values, as described in [20].

\subsection{Telaprevir concentration}

Telaprevir was measured in plasma samples by ultraperformance liquid chromatography-tandem mass spectrometry (UPLCMS/MS). Detailed information is reported in Appendix A.

\section{Results}

\subsection{Treatment outcome following telaprevir $+\operatorname{peg} I F N+R B V$ administration}

Out of 15 patients included in the study, virological-failure was detected in 3 previous null-responders $(1=$ non-response; 2 = viral-breakthrough); 1 previous relapser dropped-out at week-8 for non-virological reasons (HCV-RNA at the time of interruption <LLOD, Table 2). The other 11 patients (2 cirrhotic-naïve; 4 relapsers; 1 partial-responder; 4 null-responder) reached End of Treatment (EOT) with undetectable HCV-RNA (target not detected, TND) and are now experiencing a Sustained Virologic Response (SVR) after at least 12 weeks of follow-up.

Treatment outcome was not compromised by the baseline presence of T54S (detected in PT12, SVR 24 ), nor by Q80K (detected in PT15 and PT8, SVR $_{24}$ and $\mathrm{SVR}_{12}$ respectively).

A rapid viral response (RVR), defined as TND HCV-RNA at week4 of triple-therapy, was observed in 11/15 (73.3\%) patients. Out of 10 RVR patients who completed treatment, 9 (90.0\%) obtained a SVR vs. $2 / 4(50.0 \%)$ non-RVR patients $(P=0.176)$. All 4 patients who did not experience a RVR were previous null-responders.

\subsection{Early HCV-RNA decay following telaprevir + pegIFN $+R B V$ administration}

An initial HCV-RNA decay was already visible in 11 patients at $4 \mathrm{~h}$ since first telaprevir administration (median [IQR] HCV-RNA decay $_{\text {BL-4h }}=0.3[0.2-0.4] \log \mathrm{IU} / \mathrm{ml}$ ) (Fig. 1). HCV-RNA declined in all patients at $6 \mathrm{~h}$ (median [IQR] decay ${ }_{\mathrm{BL}-6 \mathrm{~h}}=0.6[0.6-0.8] \log \mathrm{IU} / \mathrm{ml}$ ) and at $8 \mathrm{~h}$, before taking the second dose (median [IQR] decay $_{\text {BL-8h }}=1.2[1.0-1.9] \log \mathrm{IU} / \mathrm{ml}$ ).

In a subgroup of 7 patients for whom $12 \mathrm{~h}$ HCV-RNA value was available, HCV-RNA decay showed its maximum value at this time-point (median $[\mathrm{IQR}]$ decay $_{\mathrm{BL}-12 \mathrm{~h}}=2.1[1.5-2.2] \log \mathrm{IU} / \mathrm{ml}$ ), slowing down afterwards (median [IQR] decay ${ }_{12 \mathrm{~h}-24 \mathrm{~h}}=0.5$ [0.4-0.9] $\log \mathrm{IU} / \mathrm{ml})$.
At $24 \mathrm{~h}$ after treatment start, median [IQR] HCV-RNA decline from baseline values was of 2.4 [2.2-2.7] $\log \mathrm{IU} / \mathrm{ml}$ (Fig. 1.). This decay was not affected by baseline viraemia $(P=$ n.s. by linear regression analysis), nor by HCV-subtype $1 \mathrm{a}$ or $1 \mathrm{~b}$, previous treatment experience, stage of liver disease and final virological outcome to triple-therapy (Fig. 2).

The same result was obtained also analysing the baseline-to$48 \mathrm{~h} \mathrm{HCV}$-RNA decline (Fig. 2), thus indicating that the rough value of viral decay from baseline to $48 \mathrm{~h}$ seems not to be affected by baseline clinical and virological parameters, nor to affect the rate of virological success. Nevertheless, even if the rough value of HCVRNA decay at $48 \mathrm{~h}$ was consistent among all patients, the median [IQR] slope of HCV-RNA decay between 24 and $48 \mathrm{~h}$ was significantly lower in failing-patients, respecting to SVRs $(-0.4[-0.7$; $-0.1]$ vs. $-3.3[-3.9 ;-2.9] \log \mathrm{IU} / \mathrm{ml} /$ week, respectively; $P=0.04$ by Mann-Whitney test) (Table 2).

Overall, failing-patients experienced a slowing down decay of HCV-RNA, starting from $24 \mathrm{~h}$ after treatment start. This different kinetic was maintained also during second-phase viraemia decline. Indeed, the 3 failing-patients were the only ones with $<1 \log \mathrm{IU} / \mathrm{ml}$ decline between $48 \mathrm{~h}$ and week-2 (Table 2), while all other patients had a median (IQR) decay $48 \mathrm{~h}-2 \mathrm{w}$ of $1.9(1.4-2.3) \log \mathrm{IU} / \mathrm{ml}$ $(P=0.030$ by Mann-Whitney test). At week- 2 of triple-therapy, all patients experiencing RVR (and afterwards SVR) had HCVRNA values below LLOD $(N=5)$ or $<100 \mathrm{IU} / \mathrm{ml}(N=4)$. The only RVR patient (PT9) experiencing virological-failure had HCV-RNA at week-2 of $430 \mathrm{IU} / \mathrm{ml}$ (Table 2). Interestingly, $3 / 4$ patients with HCV-RNA >100 at week-2 experienced virological-failure vs. 0/9 of those with $\mathrm{HCV}-\mathrm{RNA}<100 \mathrm{IU} / \mathrm{ml}(P=0.003$ by Fisher Exact test $)$ (Table 2).

At week-2, suboptimal viral-kinetic impacted also on rough HCV-RNA delta values from baseline, which was significantly lower in all patients experiencing virological-failure respecting to SVRs (median $[\mathrm{IQR}] \mathrm{HCV}-\mathrm{RNA}$ decay $_{\mathrm{BL}-2 \mathrm{w}}=-3.1[-3.4 ;-0.5]$ vs. -4.6 $[-4.8 ;-4.2] \log \mathrm{IU} / \mathrm{ml}$, respectively; $P=0.014$ by Mann-Whitney test) (Fig. 2).

\subsection{Viral load changes analysis using the standard model of viral dynamics}

To verify whether an alteration of first-phase/second-phase viral decline occurs in patients experiencing virological-failure, a CE model for viral-kinetics was used.

In our dataset, the mean (SE) delay time $t_{0}$ assumed for pegIFN + RBV + telaprevir triple-therapy to be effective was of 10.7 $(2.2) \mathrm{h}$, or $0.444(0.092)$ days (Table 3 ). Higher $t_{0}$ values among 
V. Cento et al. / Digestive and Liver Disease $x x x$ (2015) $x x x-x x x$
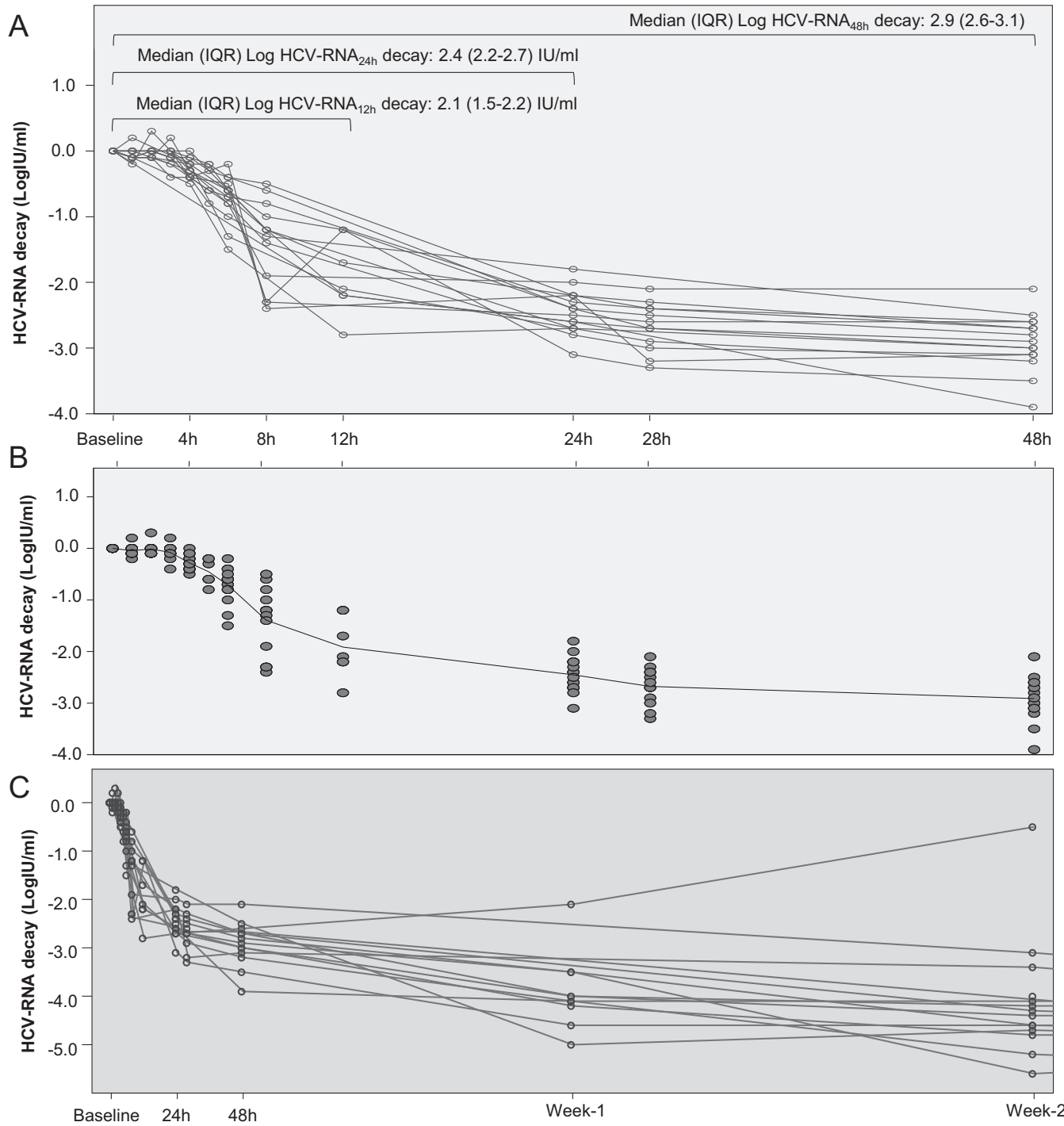

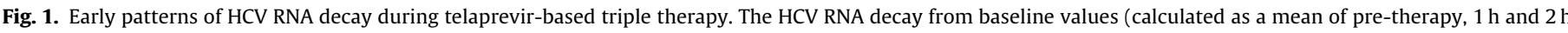

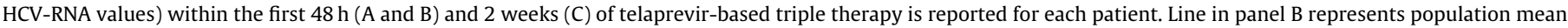
$\mathrm{IU}$, international units; IQR, interquartile range.

patients were not related to treatment outcome nor to the stage of disease progression, since it was not significantly higher in cirrhotic patients (data not shown).

The mean free virions clearance rate $(c)$, characterising firstphase HCV-RNA decline, was 9.4 day $^{-1}$ (Table 3 ). It was higher than the 5.95 day $^{-1}$ estimated with standard IFN, thus suggesting a lower duration of the first-phase of HCV-RNA drop $(<48 \mathrm{~h})$ with telaprevir.

Also the mean value of per capita rate of loss of infected cells $(\delta)$ was slightly higher than that reported with standard IFN $\left(0.22\right.$ day $^{-1}$ vs. 0.16 day $\left.^{-1}\right)$. Patients experiencing virologicalfailure tended to have lower mean $\delta$ values, and thus a slower second phase of HCV-decline, relative to patients achieving SVR (mean $[S E]=0.137[0.093] \mathrm{day}^{-1}$ vs. $0.244[0.131] \mathrm{day}^{-1}$, respectively), even if the difference was not statistically significant. Also mean treatment-effectiveness $\varepsilon$ was lower in failing patients relative to patients with SVR ( $88 \%$ vs. 94\%) (Table 3) and linear regression analysis highlighted a correlation among treatment-effectiveness $\varepsilon$ and $\delta(P=0.0133)$, sustained by Spearman's correlation coefficient $(r=0.671)$. Overall, these data confirm a suboptimal second-phase decline in therapy-failing patients.

\subsection{Telaprevir pharmacokinetics analysis in the context of cirrhosis and virological failure to triple therapy}

To evaluate the factors potentially impacting on treatmentefficacy, telaprevir plasma concentration was calculated in all patients at different time-points (6h-8h-12h-24h-48h-1w-4w): in all cases, the concentration curve was always found to be above the recommended therapeutic-ranges. Nevertheless, the peak of plasma concentration at 6-8 h since treatment start tended to be lower in cirrhotic patients (median [IQR] plasma telaprevir-concentration $=2345[1476-2692] \mathrm{ng} / \mathrm{ml}$ ) in comparison to non-cirrhotic (2701 [1658-3318] ng/ml), even if the difference was not statistically significant $(P=0.4923$ by WilcoxonTest), and did not correlate to previous treatment outcome (data not shown).

Analysing the peak (6-8h) to trough ( $24 \mathrm{~h})$ decline slope of plasma telaprevir-concentration, no differences were observed among previous relapsers or previous non-responders, if the patients were non-cirrhotic and excluding those experiencing virological-failure (Fig. 3). On the contrary, naïve cirrhotic patients tended to have lower telaprevir pharmacokinetics values at $24 \mathrm{~h}$, 

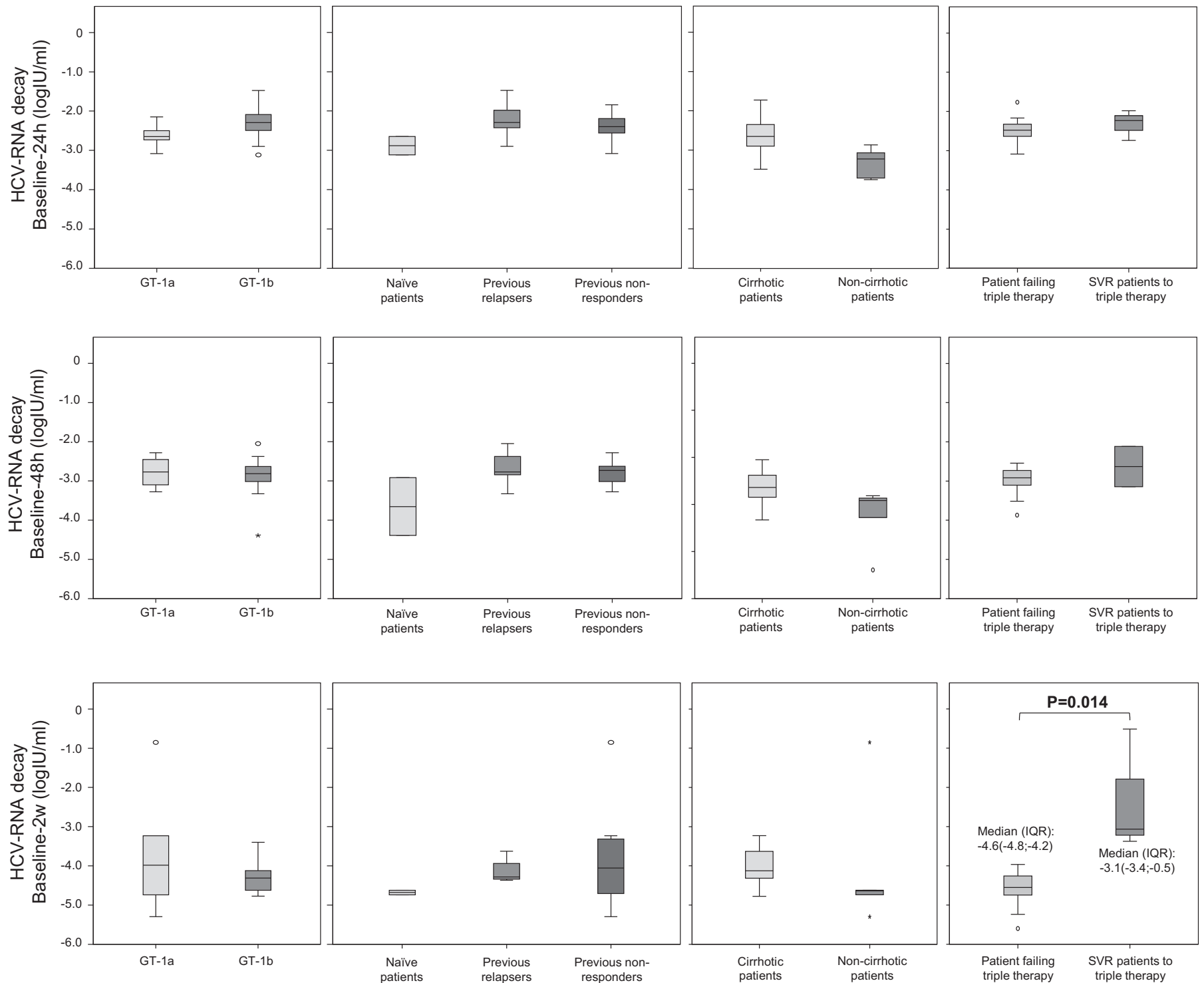

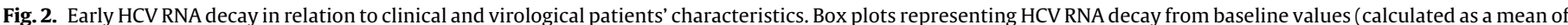

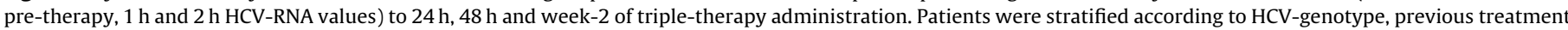

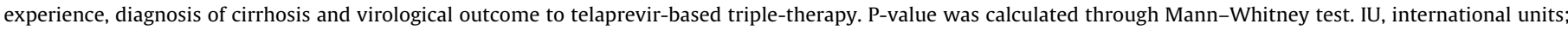
SVR, sustained virological response; IQR, interquartile range.

such those who later experienced virological-failures, who also showed a decline in concentration respecting to the $6-8 \mathrm{~h}$ peak (Fig. 3).

Therefore, we confirmed an appropriate drug-exposure during the first period of triple-therapy administration, in all 15 patients included in the study.

\subsection{HCV quasispecies evolution and drug resistance detection in the early phases of telaprevir + PegIFN + RBV administration}

To assess HCV-quasispecies rearrangement at early time points during treatment, viral evolution by population-sequencing and UDPS was performed.

By population-sequencing, viral evolution in the first hours and days since treatment start ( $8 \mathrm{~h}-24 \mathrm{~h}-48 \mathrm{~h}$ ) was low, with a median (IQR) intrapatient evolutionary divergence, between baseline and last detectable early time-point, of $0.001(0.000-0.003)$ nsubs/site. This corresponds to a median (IQR) of 1 (1-7) nucleotide variations on a total of 543 nucleotide positions analyzed.
Then, UDPS analysis was performed to better characterise the quasispecies dynamics and rearrangement. At baseline, patients experiencing virological-failure tended to have higher intra-patient nucleotide genomic complexity in comparison to SVR patients, both in terms of evolutionary-divergence (mean $[\mathrm{SD}]=0.018$ [0.009] nsubs/site vs. 0.013 [0.005], respectively, $P=0.35$ ) and Shannon Entropy (mean $[S D]=0.029[0.015] \times 10^{-3}$ vs. 0.022 $[0.010] \times 10^{-3}$, respectively).

Within the first hours, viral-quasispecies detected at baseline, remained substantially stable at all early time-points ( $8 \mathrm{~h}, 12 \mathrm{~h}, 24 \mathrm{~h}$ ), in all patients studied for this purpose, with no rearrangements of species prevalence at both nucleotide and amino acid levels (data not shown). This suggests a mutational-freeze and a limited number of (or even absent) cycles of viral replication in this observation period.

After $48 \mathrm{~h}$, still no quasispecies rearrangements were detected in SVR patients analyzed. On the contrary, in 2/2 failing-patients with available samples (PT7 and PT13), early development of resistanceassociated variants (RAVs) was observed (Supplementary Table S1). 


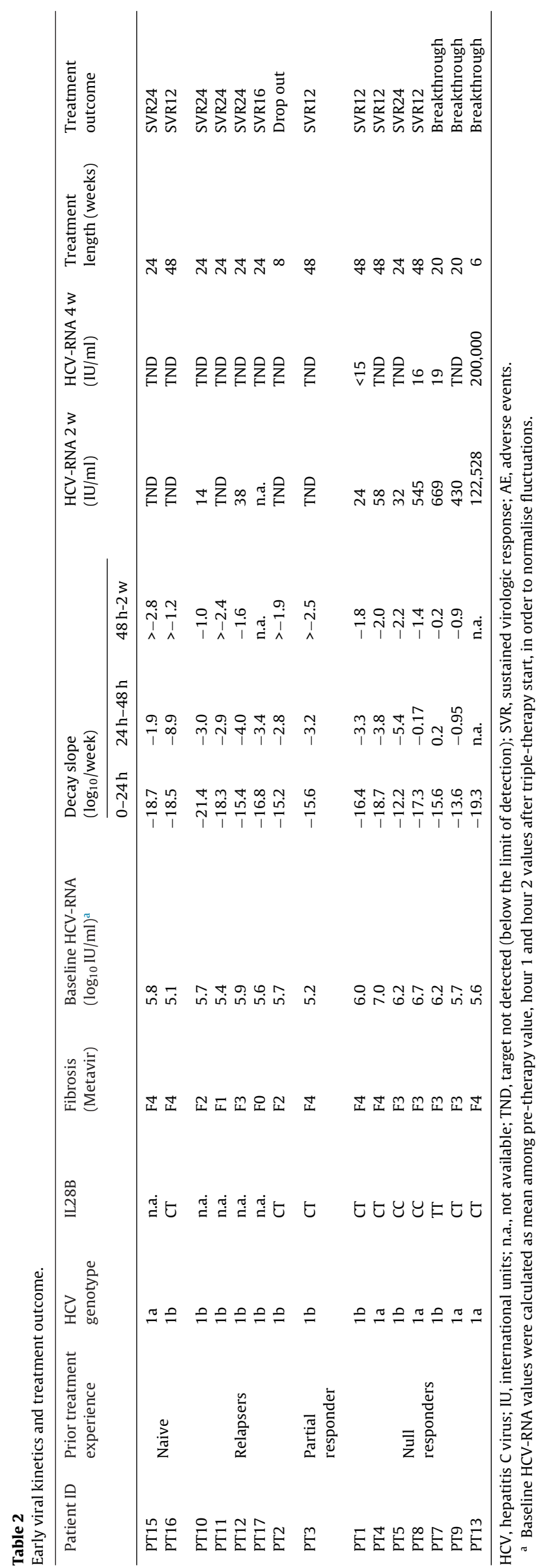

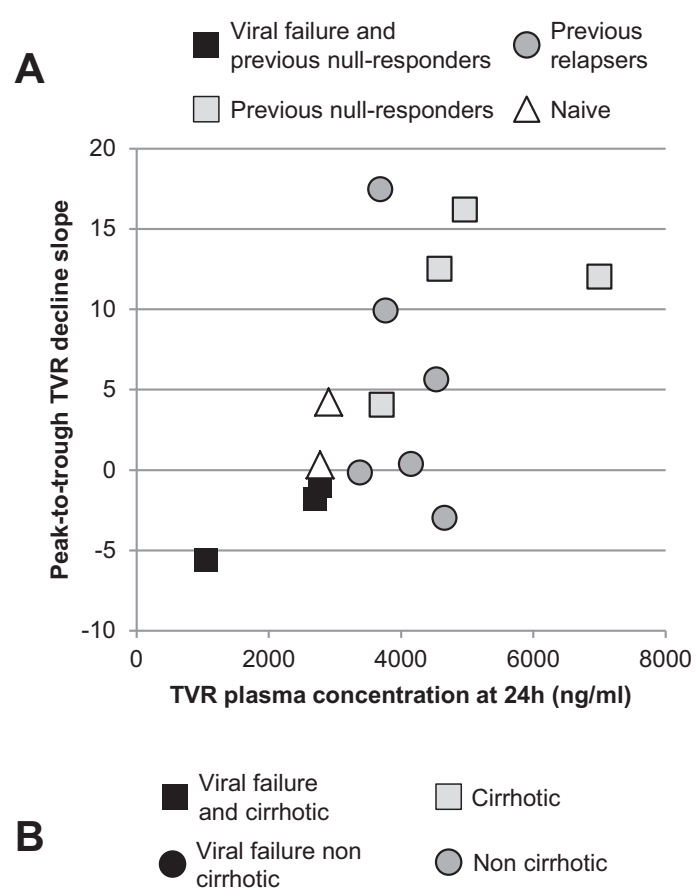

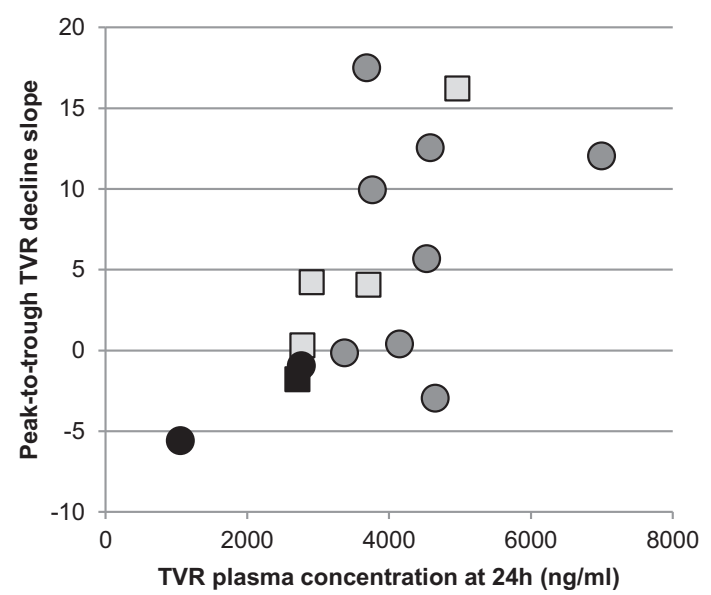

Fig. 3. Peak to trough decline slope of telaprevir plasma concentration. The peak $(6-8 \mathrm{~h})$ to trough $(24 \mathrm{~h})$ decline slope of telaprevir plasma concentration in relation to the $24 \mathrm{~h}$ value after triple-therapy start are reported for each patient. Patients were grouped according to triple-therapy outcome (black content for viral failures) and (A) previous response or (B) diagnosis of cirrhosis. TVR, telaprevir.

In PT13, the R155K accounted for 99.8\% of infecting viral population already at 2 weeks of triple therapy, and it was associated with an increase in HCV-RNA $(122,528 \mathrm{IU} / \mathrm{ml}$ vs. $728 \mathrm{IU} / \mathrm{ml}$, from $24 \mathrm{~h})$.

In PT7, experiencing late viral-breakthrough, UDPS analysis instead revealed, already at $48 \mathrm{~h}$, resistant strains only as minority-variants: V36A (459/5244 reads, $8.7 \%$ prevalence, mutational-load $=2.0 \log \mathrm{IU} / \mathrm{ml})$ and T54A $(1885 / 5248$ reads, $26.1 \%$ prevalence, mutational- $\operatorname{load}=2.5 \log \mathrm{IU} / \mathrm{ml})$. These RAVs were found later at failure, with a major prevalence of T54A (4726/5624 reads, $84.0 \%$ prevalence), and a minority contribution of V36A (49/5529 reads, $1.0 \%$ prevalence) and T54S (165/5624 reads, $2.8 \%$ prevalence).

\section{Discussion}

The kinetics of early HCV-RNA decline and quasispecies evolution under telaprevir-based triple-therapy were analysed in a small pivotal group of HCV-1 infected patients (failing previous IFN-based 
Table 3

Estimation of viral dynamic parameters using constant effectiveness model.

\begin{tabular}{|c|c|c|c|c|c|c|c|}
\hline Study ID & $\begin{array}{l}\text { Treatment } \\
\text { experience }\end{array}$ & $\begin{array}{l}\text { Initial HCV-RNA } \\
(\log \mathrm{IU} / \mathrm{ml})\end{array}$ & $\begin{array}{l}\text { Delay } \\
\left(t_{0}, \text { days }\right)^{\mathrm{a}}\end{array}$ & $\begin{array}{l}\text { Virion clearance } \\
\left(c, \text { day }^{-1}\right)^{\mathrm{b}}\end{array}$ & Efficacy $(\varepsilon, \%)^{c}$ & $\begin{array}{l}\text { Infected cell death } \\
\left(\delta, \text { day }^{-1}\right)^{\mathrm{d}}\end{array}$ & $\sigma^{2}$ \\
\hline \multicolumn{8}{|c|}{ Virological failure to telaprevir-based triple therapy } \\
\hline PT7 & Null responder & 6.2 & 0.384 & 15.0 & 85.3 & 0.034 & 2.064 \\
\hline PT9 & Null responder & 5.7 & 0.317 & 12.5 & 83.2 & 0.162 & 0.778 \\
\hline PT13 & Null responder & 5.6 & 0.347 & 11.4 & 95.0 & 0.215 & 0.587 \\
\hline \multicolumn{8}{|c|}{ Sustained virological response to telaprevir-based triple therapy } \\
\hline PT15 & Naive & 5.8 & 0.306 & 14.8 & 92.5 & 0.092 & 1.800 \\
\hline PT16 & Naive & 5.1 & 0.561 & 6.3 & 99.2 & 0.304 & 1.900 \\
\hline PT2 & Relapser & 5.7 & 0.532 & 5.5 & 97.1 & 0.445 & 1.183 \\
\hline PT10 & Relapser & 5.7 & 0.533 & 7.9 & 97.8 & 0.156 & 1.975 \\
\hline PT11 & Relapser & 5.4 & 0.372 & 10.1 & 96.0 & 0.226 & 1.495 \\
\hline PT12 & Relapser & 5.9 & 0.471 & 8.3 & 88.4 & 0.177 & 1.182 \\
\hline PT17 & Relapser & 5.6 & 0.542 & 6.5 & 97.1 & 0.250 & 1.310 \\
\hline РT3 & $\begin{array}{l}\text { Partial } \\
\text { responder }\end{array}$ & 5.2 & 0.513 & 5.8 & 96.2 & 0.449 & 0.822 \\
\hline PT1 & Null responder & 6.0 & 0.507 & 5.8 & 98.3 & 0.400 & 1.002 \\
\hline PT4 & Null responder & 7.0 & 0.518 & 7.0 & 98.5 & 0.233 & 2.160 \\
\hline PT5 & Null responder & 6.2 & 0.413 & 10.4 & 77.1 & 0.119 & 2.229 \\
\hline PT8 & Null responder & 6.7 & 0.347 & 13.6 & 88.5 & 0.079 & 2.038 \\
\hline \multicolumn{2}{|c|}{ Overall mean (SD) } & $5.9(0.5)$ & $0.444(0.092)$ & $9.4(3.4)$ & $92.7(6.7)$ & $0.223(0.129)$ & $1.502(0.557)$ \\
\hline
\end{tabular}

$\mathrm{HCV}$, hepatitis C virus; IU, international units; SD, standard deviation.

a $t_{0}$ is the pharmacological delay, representing the time after which treatment affects viral load.

b $c$ is the clearance rate of free virions in plasma, calculated by non-linear fitting of HCV-RNA decay during the first $48 \mathrm{~h}$ of triple therapy to the mathematical model.

${ }^{c} \varepsilon$ is the effectiveness of therapeutic regimen in blocking virion production. Is assumed to have a value between 0 (no effect) and 1 (100\% effective) and it was calculated by model fitting of the biphasic decline, using HCV-RNA decay during the first $48 \mathrm{~h}$ of triple therapy.

${ }^{\mathrm{d}} \delta$ is the rate at which infected cells are lost, calculated by non-linear fitting of HCV-RNA decay during the first $48 \mathrm{~h}$ of triple therapy to the mathematical model.

treatments, or with advanced liver disease), with frequent sampling at multiple time-points, including the very first hours of treatment. Our results show that first-phase HCV-RNA decline may be actually shorter than previously estimated with standard IFN-treatment [11], being comprised within the first $24 \mathrm{~h}$ since treatment-start. During this first-phase, all 15 patients experienced an effective and optimal HCV-RNA decline, with mutational-freeze, such as it occurs in more easily treatable patients, and independent from virologicaloutcome [10]. Vice versa, the second-phase of viral kinetics is in general slower than that found in easier patients [10], and even more compromised in those that experienced virological-failure.

Previous results on non-cirrhotic drug-naïve patients treated with either telaprevir-monotherapy or triple-therapy [10] have shown a much more rapid first phase and second phase HCV-RNA decline in comparison to dual IFN-based treatments [11,13].

In our population, the slope of first-phase decline was optimal and consistent with previous estimates $[11,13,10]$, thus highlighting an independence of the first HCV-RNA decay from baseline clinical and virological characteristics. In particular, the slope of HCV-RNA decay was at its height at $24 \mathrm{~h}$ after treatment start. After this time-point, the decay rate suffered a slowdown, thus assuming an early start of the second-phase kinetic. The higher potency of telaprevir in blocking viral production, respecting to IFN, can account for the shortening of first-phase decline, as supported by the higher values of treatment effectiveness $(\varepsilon)$ and free virions clearance rate $(c)[11,13]$.

During this short first-phase, HCV-RNA decay was thus deep, rapid, and, notably, consistent in all 15 patients, including those that later failed. By UDPS, no rearrangement of viral quasispecies (nor emergence of RAVs, at the lowest limit of UDPS reliability) was detected within these first $24 \mathrm{~h}$ of treatment, indicating a mutational-freeze and a limited number of (or even absent) cycles of viral replication.

On the contrary, in all 15 patients, second-phase HCV-RNA decay kinetic was characterised by values of infected cell clearance rate $(\delta)$ lower than those previously defined in naïve and non-cirrhotic patients undergoing the same treatment [10]. In particular, the mean value of $\delta$ was much lower than the value of 1.19 day $^{-1}$ reported using the same CE model in naïve patients treated with TVR-monotherapy or triple-therapy (whose determination was nevertheless considered inaccurate) and more close to the value of 0.58 day $^{-1}$ calculated using a varying-effectiveness model [10]. In addition, while first-phase decay was identical among SVRs and failing-patients, after $24 \mathrm{~h}$ significant differences started to appear. Indeed, in all telaprevir-failing patients the second-phase viraldecline was characterised by a poor (or null) $24 \mathrm{~h}-48 \mathrm{~h}$ and $48 \mathrm{~h}-2 \mathrm{w}$ HCV-RNA declines, and resulted in HCV-RNA values $>100 \mathrm{IU} / \mathrm{ml}$ at week-2.

Independent from baseline viraemia, 3/4 patients with HCVRNA $>100 \mathrm{IU} / \mathrm{ml}$ at week-2 failed triple-therapy. In agreement with this result, in a larger dataset of telaprevir- and boceprevir-treated patients $(N=83)$, we recently reported that week-2 HCV-RNA decay is significantly lower in patients experiencing virologicalfailure than in SVRs (median $[\mathrm{IQR}]=-3.7[-4.3 ;-3.2]$ vs. -4.6 $[-5.2 ;-4.0] \log \mathrm{IU} / \mathrm{ml}, P=0.007)$ and that $\mathrm{HCV}-\mathrm{RNA}>100 \mathrm{IU} / \mathrm{ml}$ at week-2 is significantly associated with virological-failure (adjusted OR: 27.955; 95\% C.I.: 1.885-414.500; $P=0.015$ ), after correction by baseline/early RAVs, HCV-subtype, cirrhosis, unfavourable IL28B and previous null-response [21]. Thus, assessment of HCV-RNA at week-2 may actually represent a good proxy for virological-response, promptly identifying patients at higher risk of virological-failure if higher than $100 \mathrm{IU} / \mathrm{ml}$.

The suboptimal second-phase HCV-RNA decline observed in failing-patients can be associated to a lower $\delta$, and/or to a lower $\varepsilon$. As previously reported [10], we indeed observed a direct correlation among $\varepsilon$ and $\delta$. This indicates that, within biological limits, the second slope of viral decline is improved as drugeffectiveness improves. The base mechanism of this phenomenon lies in the hypothesis that the second-phase HCV-RNA decline may be driven not only by loss of infected cells, but also by a continuous decline in viral production and "cell cure" via riddance of intracellular replication complexes [16]. Therefore, 
suboptimal treatment-effectiveness can slower the second-phase decline independently of immune response, increasing the risk of virological-failure.

A lower treatment efficacy is probably dependent by multiple factors, such as: (a) the suboptimal action of pegIFN + RBV backbone, supported by the fact that all 3 failing-patients were previous null-responders and with unfavourable IL28B genotype; (b) by the poorer telaprevir-pharmacokinetics (indeed observed in all 3 failing patients); and (c) selection or development of RAVs, further affecting drug-effectiveness during the course of treatment [6].

Whatever the mechanism, lower $\varepsilon$ and $\delta$ values in both patients experiencing late viral-breakthrough corresponded to the lowest 24h-2w HCV-RNA decay slopes. Assuming a complete therapymediated control of viral replication $(\varepsilon=100 \%)$, this decay pattern could simply represent a delay in infected cell clearance, and thus just underlie the utility of a longer treatment. Since also $\varepsilon$ is reduced, however, the chance of low-level viral replication under drug-pressure is high, possibly allowing the development/selection of minority RAVs. Indeed, early rearrangement of viral quasispecies occurred exclusively in failing-patient, and it was associated with the development of RAVs at failure. During second-phase viral decline, mutational-freeze was thus no longer observed in patients experiencing virological-failure, since RAVs were detected in 2/2 analyzed patients between $48 \mathrm{~h}$ and 2 weeks, though with different prevalence.

In PT7, experiencing late viral breakthrough, RAVs were already detected at $48 \mathrm{~h}$ just as minor variants, and became the most prevalent viral population only at the moment of failure (week-20). These $48 \mathrm{~h}$ minority RAVs were completely absent at earlier evaluations ( $8 \mathrm{~h}$ and $24 \mathrm{~h}$ ), suggesting a process of development and selection, rather than pure selection of pre-existent RAVs, at least when late failure occurs.

On the other hand, in PT13, RAVs detected at week-2 accounted for $99.8 \%$ of infecting viral population, and indeed determined an increase in HCV-RNA from previous values. This pattern may suggest in this patient the pre-existence of minority RAVs. Unfortunately, no $24 \mathrm{~h}-48 \mathrm{~h}$ samples were available for PT13 and, at baseline, no evidences of resistance were found. Nevertheless, the absence of RAVs detection at baseline doesn't exclude their minor presence, below the sensitivity-limit of UDPS ( $<0.1 \%$ prevalence). In PT13, for instance, $0.1 \%$ of baseline $440,465 \mathrm{IU} / \mathrm{ml}$ would correspond to $440 \mathrm{IU} / \mathrm{ml}$, thus still $2.6 \mathrm{log} \mathrm{IU} / \mathrm{ml}$ of circulating potentially resistant strains, even if this hypothesis needs to be confirmed by means of more sensitive techniques (such as illumina).

For the present study, week-2 $100 \mathrm{IU} / \mathrm{ml}$ threshold was evaluated by Roche $\operatorname{COBAS}^{\circledR}$ TaqMan ${ }^{\circledR}$ HCV Test v2.0 assay. Although this assay and Abbott RealTime HCV assay have different sensitivity, they show high clinical concordance [22]. Indeed, in another study on a larger population we confirmed the same threshold with both tests [21].

In conclusion, now more than ever, clinical management of HCV-infected patients treated with first-generation PIs may benefit from a closer and accurate early virological-monitoring, given the rapid kinetics of HCV-RNA decline and the risk of resistancedevelopment. For this reason HCV-RNA measurements performed during second-phase HCV-RNA decline (i.e. at week-2) under tripletherapy may provide relevant clinical information to monitor treatment efficacy. Suboptimal early HCV-RNA decline from $48 \mathrm{~h}$ to the first 2 weeks of treatment may indeed be the first hint for an ongoing residual viral replication under pharmacological-pressure, potentially leading to development and selection of resistance, and, eventually, virological failure.

\section{Conflict of interest}

P. Navarra, M. Angelico, C.F. Perno and F. Ceccherini-Silberstein have received funds for attending symposia, speaking, organizing educational activities, grant research support, consultancy and advisory board membership, from ViiV and Merck Sharp \& Dohme (PN), from Roche, Gilead, Merck Sharp \& Dohme, Janssen Cilag (MA), form Abbott, Boehringer Ingelheim, Bristol Myers Squibb, Gilead, Merck Sharp \& Dohme, Janssen Cilag, Pfizer, Tibotec, Roche, and ViiV (CFP), and from Abbvie, Merck Sharp \& Dohme, Gilead, Janssen Cilag, Roche, Bristol Myers Squibb, and ViiV (FCS).

The other authors of this study do not have anything to disclose regarding funding from industry or conflicts of interest.

\section{Acknowledgments}

This work was supported by the Italian Ministry of Instruction, University and Research (MIUR) [RBAP11YS7K_001, and PB05] and by Aviralia Foundation. The funders had no role in study design, data collection and analysis, decision to publish, or preparation of the manuscript.

We thank Roche for providing laboratory material for HCVRNA determination, the Clinical Hepatology and Molecular Virology groups of "Tor Vergata" University Hospital, and particularly Daniele Di Paolo, Domenico di Carlo and Francesca Stafoggia for statistical, clinical and technical support.

\section{Appendix A. Supplementary data}

Supplementary data associated with this article can be found, in the online version, at http://dx.doi.org/10.1016/j.dld.2014.12.004.

\section{References}

[1] Bacon BR, Gordon SC, Lawitz E, et al. Boceprevir for previously treated chronic HCV genotype 1 infection. New England Journal of Medicine 2011;364:1207-17.

[2] Jacobson IM, McHutchison JG, Dusheiko G, et al. Telaprevir for previously untreated chronic hepatitis C virus infection. New England Journal of Medicine 2011;364:2405-16

[3] Poordad F, McCone Jr J, Bacon BR, et al. Boceprevir for untreated chronic HCV genotype 1 infection. New England Journal of Medicine 2011;364: 1195-206.

[4] Zeuzem S, Andreone P, Pol S, et al. Telaprevir for retreatment of HCV infection. New England Journal of Medicine 2011;364:2417-28

[5] Pawlotsky JM. Treatment failure and resistance with direct-acting antiviral drugs against hepatitis C virus. Hepatology 2011;53:1742-51.

[6] Soriano V, Perelson AS, Zoulim F. Why are there different dynamics in the selection of drug resistance in HIV and hepatitis B and C viruses? Journal of Antimicrobial Chemotherapy 2008;62:1-4.

[7] Ribeiro RM, Li H, Wang S, et al. Quantifying the diversification of hepatitis C virus (HCV) during primary infection: estimates of the in vivo mutation rate. PLoS Pathogens 2012;8:e1002881.

[8] Martell M, Esteban JI, Quer J, et al. Hepatitis C virus (HCV) circulates as a population of different but closely related genomes: quasispecies nature of $\mathrm{HCV}$ genome distribution. Journal of Virology 1992;66:3225-9.

[9] Rong L, Dahari H, Ribeiro RM, et al. Rapid emergence of protease inhibitor resistance in hepatitis C virus. Science Translational Medicine 2010:2:30ra32.

[10] Guedj J, Perelson AS. Second-phase hepatitis C virus RNA decline during telaprevir-based therapy increases with drug effectiveness: implications for treatment duration. Hepatology 2011:53:1801-8

[11] Neumann AU, Lam NP, Dahari H, et al. Hepatitis C viral dynamics in vivo and the antiviral efficacy of interferon-alpha therapy. Science 1998;282: 103-7.

[12] Rosen HR, Ribeiro RR, Weinberger L, et al. Early hepatitis C viral kinetics correlate with long-term outcome in patients receiving high dose induction followed by combination interferon and ribavirin therapy. Journal of Hepatology 2002:37:124-30

[13] Dixit NM, Layden-Almer JE, Layden TJ, et al. Modelling how ribavirin improves interferon response rates in hepatitis C virus infection. Nature 2004;432: 922-4.

[14] Chatterjee A, Guedj J, Perelson AS. Mathematical modelling of HCV infection: what can it teach us in the era of direct-acting antiviral agents? Antiviral Therapy 2012;17(Pt B):1171-82.

[15] European Medicines Agency (EMA). Incivek (telaprevir) Film Coated Tablets. EU Prescibing Information; 2011 May 1.

[16] Guedj J, Neumann AU. Understanding hepatitis C viral dynamics with direct-acting antiviral agents due to the interplay between intracellular 
replication and cellular infection dynamics. Journal of Theoretical Biology 2010;267:330-40

[17] Cento V, Mirabelli C, Salpini R, et al. HCV genotypes are differently prone to the development of resistance to linear and macrocyclic protease inhibitors. PLoS ONE 2012;7:e39652.

[18] Zagordi O, Bhattacharya A, Eriksson N, et al. ShoRAH: estimating the genetic diversity of a mixed sample from next-generation sequencing data. BMC Bioinformatics 2011;12:119.

[19] Tamura K, Peterson D, Peterson N, et al. MEGA5: molecular evolutionary genetics analysis using maximum likelihood, evolutionary distance, and maximum parsimony methods. Molecular Biology and Evolution 2011;28:2731-9.
[20] Nasu A, Marusawa H, Ueda Y, et al. Genetic heterogeneity of hepatitis C virus in association with antiviral therapy determined by ultra-deep sequencing. PLoS ONE 2011;6:e24907.

[21] Cento V, Di Maio VC, Di Paolo D, et al. NS3-resistance in advanced HCV patients treated with BOC/TRV-based therapy: impact on virological failure of baseline and early time points. The Liver Meeting 2013, AASLD Abstracts. Hepatology 2013;58(Suppl. 1):1960.

[22] Taylor N, Haschke-Becher E, Greil R, et al. Performance characteristics of the COBAS Ampliprep/COBAS TaqMan v2.0 and the Abbott RealTime hepatitis C assays - implications for response-guided therapy in genotype 1 infections. Antiviral Therapy 2014;19:449-54. 